\title{
ADPCM Image Compression Techniques for Remote Sensing Applications
}

\author{
Ashok Kumar*, Rajiv Kumaran, Sandip Paul, Sanjeev Mehta \\ Scientist/Engineer, Space Applications Centre, Indian Space Research Organization, Jodhpur Tekra, Ahmedabad, India- \\ 380015 \\ *Email: ashokkumar@sac.isro.gov.in
}

\begin{abstract}
ISRO's remote sensing continuity mission Resourcesat-II provided better radiometric performance as compared to Resourcesat-I. However, this improvement required implementation of onboard image compression techniques to maintain same transmission interface. In LISS-4 payload, prediction based DPCM technique with 10:7 compression ratio was implemented. Based on received data from this payload, some ringing artifacts were reported at high contrast targets, which degrade image quality significantly. However occurrences of such instances were very few. For future missions, efforts are made to develop an improved low complex image compression technique with better radiometry and lesser artifacts. Adaptive DPCM (ADPCM) technique provides better radiometric performance. This technique has been implemented onboard by other space agencies with their own proprietary algorithm. To maintain existing 10:7 compression ratio, novel ADPCM techniques with adaptive quantizers are developed. Developed ADPCM techniques are unique w.r.t. predictor and encoding. Developed techniques improve RMSE from 1.3 to 10 times depending on image contrast. Ringing artifacts are reduced to $1 \%$ from $38 \%$ with previous technique. Developed techniques are of low complexity and can be implemented in low end FPGA.
\end{abstract}

Index Terms-DPCM, RMSE, Dynamic Range, Compression.

\section{INTRODUCTION}

Due to recent advancement in sensor technology, ISRO's future remote sensing systems will have better spatial, radiometric, and spectral resolution. This improvement leads to higher data volume. Image compression is usually employed to meet transmission capability in space missions [1]. Compression ratio is usually decided by trade-off studies between available satellite resources and image quality requirement from user community.

DPCM, a prediction based image data compression techniques, has been used in many missions. Table-1 provides usage summary for DPCM and its adaptive part ADPCM [1].
Table 1. Usage of DPCM technique onboard

\begin{tabular}{|c|c|c|c|c|}
\hline Satellite & $\begin{array}{l}\text { Compressio } \\
\text { n Algorithm }\end{array}$ & \multicolumn{2}{|c|}{$\begin{array}{c}\text { Compression } \\
\text { Ratio }\end{array}$} & $\begin{array}{l}\text { Implem } \\
\text { entation }\end{array}$ \\
\hline $\begin{array}{l}\text { SPOT-I/II/III/IV } \\
\text { (CNES1986/90/93/9 } \\
8)\end{array}$ & \multirow{2}{*}{$\begin{array}{l}\text { Fixed Rate } \\
\text { DPCM }\end{array}$} & $8: 6$ & 1.33 & - \\
\hline $\begin{array}{l}\text { Resourcesat-II } \\
\text { (ISRO 2011) }\end{array}$ & & $10: 7$ & 1.41 & FPGA \\
\hline LANDSAT-7 (M7) & \multirow{4}{*}{$\begin{array}{l}\text { ADPCM } \\
\text { Kodak }\end{array}$} & $8: 1.5$ & $2.5,5$ & - \\
\hline $\begin{array}{ll}\text { IKONOS } & \text { (US } \\
\text { GeoEye1999) } & \end{array}$ & & $11: 2.5$ & 4.4 & ASIC \\
\hline $\begin{array}{l}\text { QuickBird (US } \\
\text { DigitalGlobe 2001) }\end{array}$ & & 11:X & - & Kodak \\
\hline $\begin{array}{l}\text { WorldView-1 (US } \\
\text { DigitalGlobe2007) }\end{array}$ & & $11: 4$ & $\begin{array}{c}2.75, \\
4.3\end{array}$ & $\begin{array}{l}\text { ASIC } \\
\text { Kodak }\end{array}$ \\
\hline $\begin{array}{l}\text { Chang'E-1 } \\
\text { (China2007) }\end{array}$ & $\begin{array}{l}\text { Differential } \\
\text { Predictive } \\
\text { (DPCM) }\end{array}$ & - & 2 & FPGA \\
\hline
\end{tabular}

In Resourcesat-2 (ISRO-2011) LISS-4 payload, DPCM technique was used with compression ratio of 10:7 [2]. This availability of 10-bit radiometric data leads to better image quality as compared to Resourcesat-1 (7-bit digitization) [3, 4]. Fig. 1 shows few onboard images (False Color image after fusion of multi-spectral data).

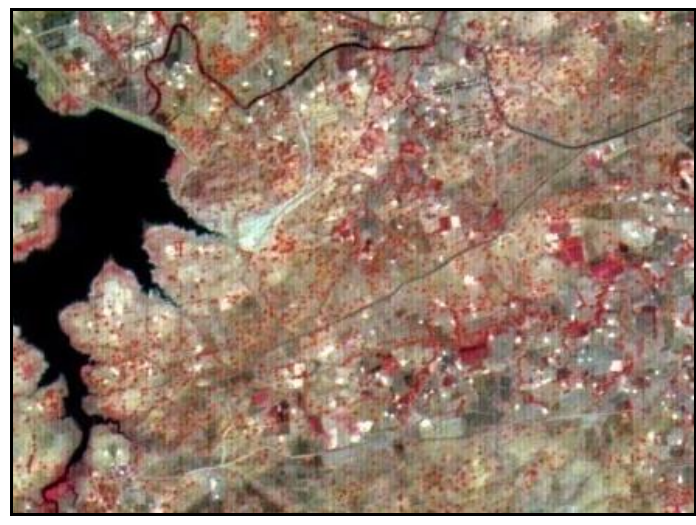

Fig. 1. Resourcesat-2 LISS-4 images

Fig. 2 shows typical histogram of an LISS-4 image (12000X12000). Kindly observe the non-linear axis. 


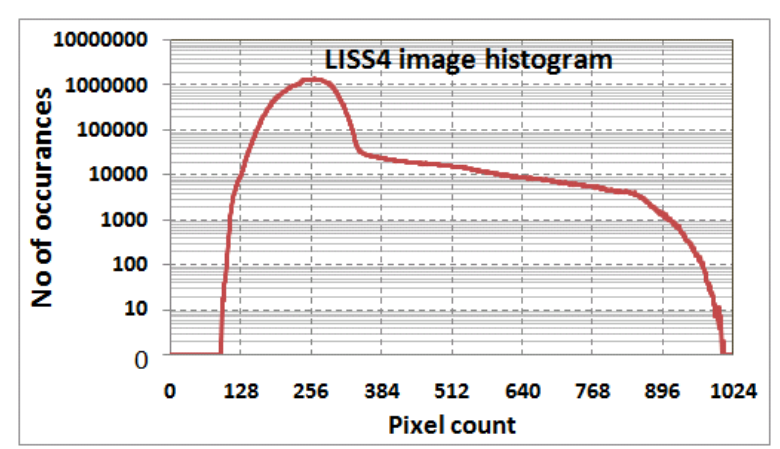

Fig. 2. Histogram of LISS-4 data

Implemented DPCM technique has quantizer dynamic range of 270 pixel difference counts, which was derived based on analysis of various payload images. But, difference count up to 600 was observed due to higher system MTF performance, which indicates that ringing artifacts are expected at high contrast locations [3]. Higher dynamic range of quantizer may force radiometric degradation at lower contrast locations. Existing technique also causes error propagation in recovery of $25 \%$ pixels [3].

Issue of ringing artifacts at high contrast and radiometric degradation at low contrast can be resolved by multiple quantizers with selective application per group [4]. Quantizer with small step size should be applied for low contrast groups. This ensures better radiometric performance considering higher probability of such instances (75-98\%) in remote sensing images. Quantizer with bigger step size should be applied for high contrast groups. This ensures lesser ringing artifacts. Requirement of multiple quantizer leads to adaptive DPCM (ADPCM) compression technique. Proprietary ADPCM algorithms had been implemented in LANDSAT, IKONOS and Quickbird missions [1]. For LISS-4 compression ratio of 10:7, custom ADPCM techniques with adaptive quantization are developed. This paper provides details of existing DPCM technique and newly developed ADPCM techniques with simulation results. Section II provide details of existing DPCM technique in LISS_IV payload. Section-III provides details of newly developed ADPCM techniques ADPCM-4P \& ADPCM-5P. RMSE \& Ringing artifacts results are shown in section IV \& V respectively.

\section{EXISITING DPCM TECHNIQUE IN LISS-4 PAYLOAD}

Block diagram of existing DPCM encoder/decoder [2$4]$ is shown in Fig. 3. DPCM is implemented in a group of pixels. In a single group, at least one pixel is transmitted in its original form (lossless). For remaining pixels, residue with predictor is quantized and transmitted [5].

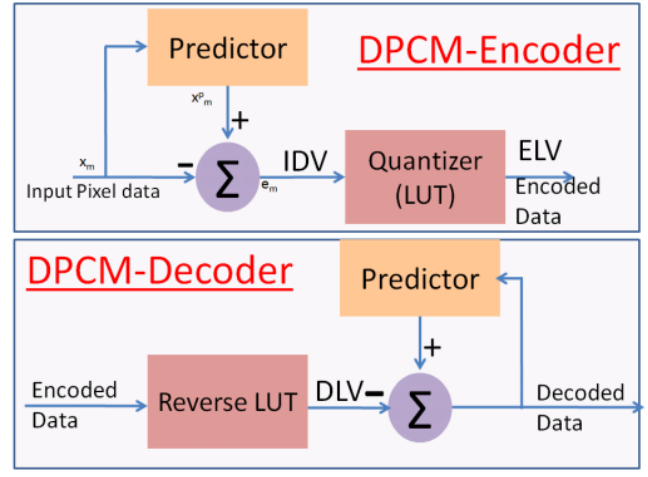

Fig. 3. Existing DPCM block diagram

Algorithm of existing DPCM technique is shown in Table 2. DPCM technique is applied separately on odd and even ports to eliminate effect of port level gain/offset variation. A group of 4 adjacent pixels e.g. P1, P3, P5 \& P7 for odd port is processed at a time. Hence, real time data compression is carried out on ADC output data directly with no external memory. For P1, P5 \& P7 pixels the 6-bit difference value (residue) will be transmitted. This difference value will occupy $>6$ bits, hence a piecewise linear quantization table (LUT: Look up Table) is prepared to retain the information at low differences (vegetation) at the expense of some loss at higher differences (cloud \& snow) [3]. Implemented quantizer is shown in Fig. 4. Even pixels are processed in similar way.

Table 2: Algorithm of Existing DPCM Technique

\begin{tabular}{|c|c|c|c|c|}
\hline \multicolumn{5}{|c|}{ DPCM operation for Odd Pixel Group } \\
\hline Input odd port data & $\begin{array}{c}\text { P1 } \\
\text { (10-bit) }\end{array}$ & $\begin{array}{c}\text { P3 } \\
\text { (10-bit) }\end{array}$ & $\begin{array}{c}\text { P5 } \\
\text { (10-bit) }\end{array}$ & $\begin{array}{l}\text { P7 } \\
(10- \\
\text { bit })\end{array}$ \\
\hline DPCM Operation & $\mathrm{P} 1-\mathrm{P} 3$ & Ref Pixel & $\mathrm{P} 3-\mathrm{P} 5$ & $\begin{array}{c}\text { P5 - } \\
\text { P7 }\end{array}$ \\
\hline $\begin{array}{l}\text { Output bits after } \\
\text { LUT mapping \& } \\
\text { adding sign bit }\end{array}$ & 6-bit & $\begin{array}{c}\text { Original } \\
\text { (Lossless) } \\
\text { 10-bit }\end{array}$ & 6-bit & 6-bit \\
\hline \multicolumn{5}{|c|}{ DPCM operation for Even Pixel Group } \\
\hline Input even port data & $\begin{array}{c}\text { P2 } \\
\text { (10-bit) }\end{array}$ & $\begin{array}{c}\text { P4 } \\
\text { (10-bit) }\end{array}$ & $\begin{array}{c}\text { P6 } \\
\text { (10-bit) }\end{array}$ & $\begin{array}{l}\text { P8 } \\
(10- \\
\text { bit })\end{array}$ \\
\hline DPCM Operation & $\mathrm{P} 2-\mathrm{P} 4$ & P4- P6 & $\begin{array}{c}\text { Ref } \\
\text { Pixel }\end{array}$ & $\begin{array}{c}\text { P6- } \\
\text { P8 }\end{array}$ \\
\hline $\begin{array}{l}\text { Output bits after } \\
\text { LUT mapping \& } \\
\text { adding sign bit }\end{array}$ & 6-bit & 6-bit & $\begin{array}{c}\text { Original } \\
\text { (Lossles } \\
\text { s) } \\
\text { 10-bit }\end{array}$ & 6-bit \\
\hline
\end{tabular}

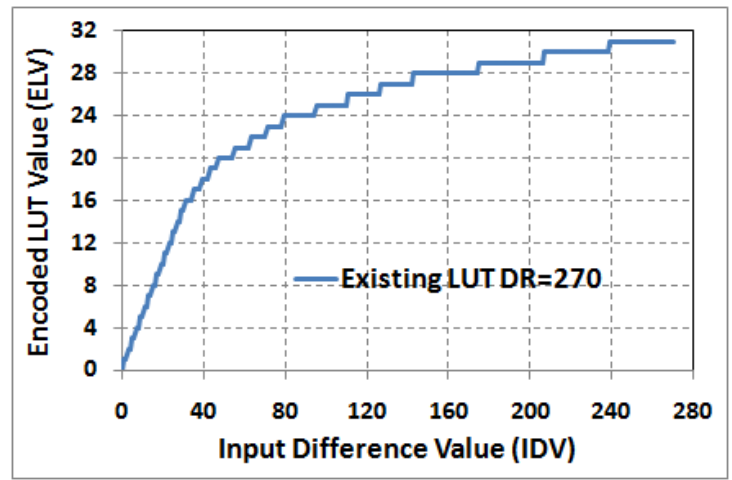

Fig. 4. Existing DPCM's Quantizer (LUT) 
Input Difference Value (IDV) i.e. the DPCM residue P1-P3 or similar is quantized through LUT and 6-bit (including one sign bit) Encoded LUT value (ELV) is generated. One of the pixels is sent without processing. Hence $25 \%$ data will be recovered losslessly.

Existing DPCM technique is developed with quantizer dynamic range of 270 IDV only, which was derived based on analysis of various payload images. But, IDV up to 600 count is possible due to higher system MTF performance, which indicates that ringing artifacts are expected at high contrast locations [3]. Dynamic range of existing LUT can be increased through bigger quantization step sizes, but this will degrade radiometric performance. Another issue with existing DPCM technique is error propagation i.e. error in recovery of P5 pixel affects $\mathrm{P} 7$ pixel's recovery.

The issue of dynamic range coverage and radiometric performance can be resolved by multiple quantizers. Quantizers will be applied selectively as per input contrast per group. Quantizer with small step size will be applied at low contrast location; this will ensure better radiometric performance considering higher probability of such instances (60-90\%). Quantizer with bigger step size will be applied at high contrast location. This will cover input dynamic range and reduce ringing artifacts. Requirement of multiple quantizers leads to Adaptive DPCM (ADPCM) technique, which is discussed in next section.

\section{DEVELOPMENT OF ADPCM TECHNIQUES FOR LISS-4 PAYLOAD DATA CONFIGURATION}

Because of lower complexity, ADPCM with adaptive quantizer is considered for development [5]. In single ADPCM group, one pixel is transmitted in original form (lossless) [5]. For remaining pixels, residue i.e. difference with predictor is quantized by look up table (LUT). Fig. 5 shows block diagram of ADPCM technique.
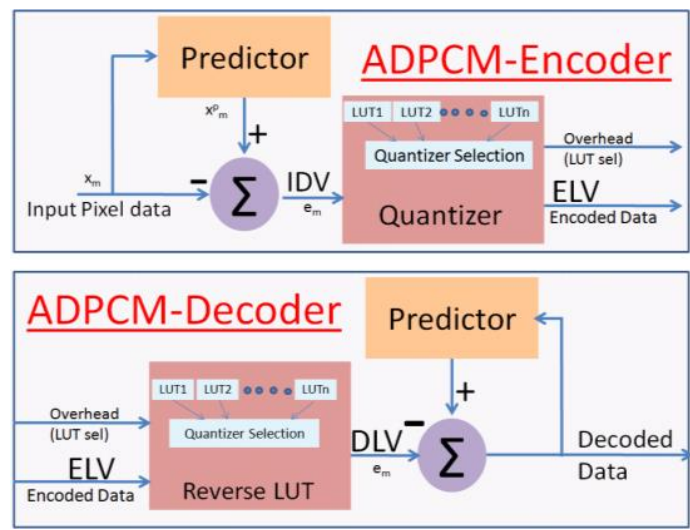

Fig. 5. ADPCM block diagram

Group size selection is also a crucial factor in ADPCM performance. Smaller group size produces lesser prediction error, but poorer compression ratio. However, bigger group size causes better compression ratio, but more prediction error. Existing DPCM technique has pixel group size of 4 . Here, ADPCM techniques are developed with pixel group size $4 \& 5$ and these are termed as ADPCM-4P \& ADPCM-5P respectively. Due to ADPCM processing of across track data only, real time compression is possible on video processor output data directly without any onboard memory. ADPCM techniques are applied separately on odd and even pixels to eliminate effect of CCD port level variation.

\section{A. Development of ADPCM-4P technique}

ADPCM-4P technique requires compression of 4-pixel 40-bit data to 28-bit. One reference pixel will occupy full 10-bits. Three input difference values (IDV) i.e. DPCM residue are quantized through selected LUT. This generates three 6-bit (including sign bit) encoded LUT values (ELV). Hence, no spare bit is available to indicate used LUT in ADPCM. Requirement of 3 sign bit transmission can be omitted if all IDVs are positive. This is possible by selecting the pixel with smallest value as a predictor for remaining three pixels. But, predictor location information has to be transmitted along the encoded data which will require additional 2-bits. The remaining 1-bit can be used for LUT selection. Encoding of proposed ADPCM-4P technique for an odd pixel group is shown in Table 3 with all four combinations.

Table 3. Encoding of Proposed ADPCM-4P

\begin{tabular}{|c|c|c|c|c|c|c|c|}
\hline $\begin{array}{l}\text { REF } \\
\text { Pixel }\end{array}$ & $\begin{array}{l}\text { ODD } \\
\text { Pixels }\end{array}$ & $\begin{array}{l}\text { P1 } \\
\text { (10- } \\
\text { hit) }\end{array}$ & $\begin{array}{c}\text { P3 } \\
\text { (10-bit) }\end{array}$ & $\begin{array}{c}\text { P5 } \\
\text { (10-bit) }\end{array}$ & $\begin{array}{l}\text { P7 } \\
(10- \\
\text { hit) }\end{array}$ & $\begin{array}{l}\text { REF } \\
\text { index }\end{array}$ & $\begin{array}{l}\text { SEL } \\
\text { LUT }\end{array}$ \\
\hline P1 & \multirow{4}{*}{ 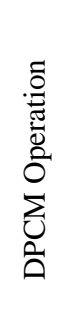 } & $\begin{array}{c}\text { P1 } \\
\text { (10-bit) }\end{array}$ & $\begin{array}{c}\text { P3-REF } \\
\text { (5-bit) }\end{array}$ & $\begin{array}{c}\text { P5-REF } \\
\text { (5-bit) }\end{array}$ & $\begin{array}{c}\text { P7-REF } \\
\text { (5-bit) }\end{array}$ & $\begin{array}{c}00 \\
\text { (2-bit) }\end{array}$ & \multirow{4}{*}{$n \frac{\overparen{B}}{1}$} \\
\hline P3 & & $\begin{array}{c}\text { P1-REF } \\
\text { (5-bit) }\end{array}$ & $\begin{array}{c}\text { P3 } \\
\text { (10-bit) }\end{array}$ & $\begin{array}{l}\text { P5-REF } \\
\text { (5-bit) }\end{array}$ & $\begin{array}{c}\text { P7-REF } \\
\text { (5-bit) }\end{array}$ & $\begin{array}{c}01 \\
\text { (2-bit) }\end{array}$ & \\
\hline P5 & & $\begin{array}{c}\text { P1-REF } \\
\text { (5-bit) }\end{array}$ & $\begin{array}{c}\text { P3-REF } \\
\text { (5-bit) }\end{array}$ & $\begin{array}{c}\text { P5 } \\
\text { (10-bit) }\end{array}$ & $\begin{array}{c}\text { P7-REF } \\
\text { (5-bit) }\end{array}$ & $\begin{array}{c}10 \\
\text { (2-bit) }\end{array}$ & \\
\hline P7 & & $\begin{array}{c}\text { P1-REF } \\
\text { (5-bit) }\end{array}$ & $\begin{array}{c}\text { P3-REF } \\
\text { (5-bit) }\end{array}$ & $\begin{array}{c}\text { P5-REF } \\
\text { (5-bit) }\end{array}$ & $\begin{array}{c}\text { P7 } \\
\text { (10-bit) }\end{array}$ & $\begin{array}{c}11 \\
\text { (2-bit) }\end{array}$ & \\
\hline
\end{tabular}

For low contrast group, lossless LUT (LUT-DR-31) is applied. This means IDV values are transmitted without any losses. For high contrast group, lossy piecewise linear LUT (LUT-DR-600) is applied. LUT-DR-600 will cover full input dynamic range and helps in avoiding ringing artifacts. Fig. 6 shows details of both these LUTs. Proposed LUTs commensurate with expected IDV histogram, shown in Fig. 7. Kindly observe non-linear axis in plot.

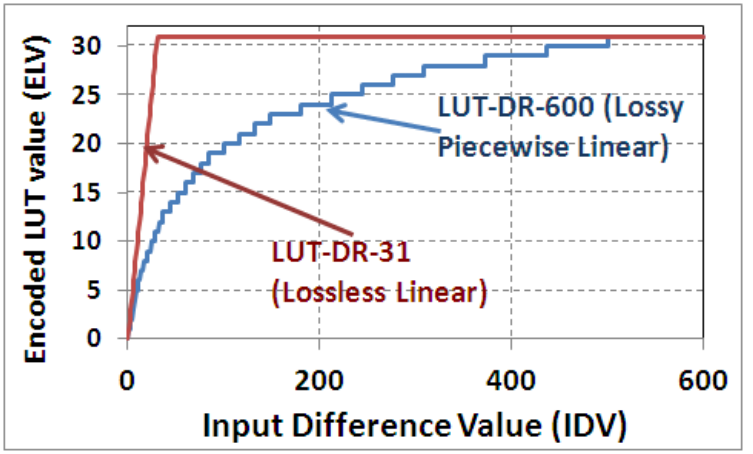

Fig. 6. Proposed ADPCM's Quantizer Details 


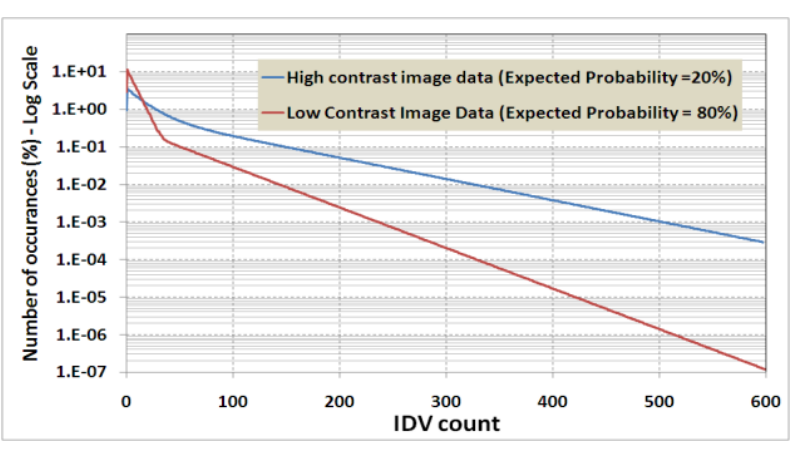

Fig. 7. Histogram of expected IDV counts

One of the main advantages of this technique is zero error propagation. However, this leads to poor prediction because reference pixel can be one of the four pixels. If it is $\mathrm{P} 1$ or $\mathrm{P} 7$, then poor correlation may increase residues and then quantization errors. Requirement of pixel sorting slightly increases hardware implementation complexity.

\section{B. Development of ADPCM-5P technique}

Algorithm of proposed ADPCM-5P technique for an odd pixel group is shown in Table 4. A group of 5 adjacent pixels is processed at a time. Details of required quantizers are already mentioned in Fig. 6.

Table 4. Algorithm of Proposed ADPCM-5P

\begin{tabular}{|c|c|c|c|c|c|c|}
\hline $\begin{array}{c}\text { Odd } \\
\text { Pixels }\end{array}$ & $\begin{array}{c}\text { P1 } \\
\text { (10-bit) }\end{array}$ & $\begin{array}{c}\text { P3 } \\
\text { (10-bit) }\end{array}$ & $\begin{array}{c}\text { P5 } \\
\text { (10-bit) }\end{array}$ & $\begin{array}{c}\text { P7 } \\
\text { (10-bit) }\end{array}$ & $\begin{array}{c}\text { P9 } \\
\text { (10-bit) }\end{array}$ & $\begin{array}{c}\text { SEL } \\
\text { LUT }\end{array}$ \\
\hline $\begin{array}{c}\text { DPCM } \\
\text { Operation }\end{array}$ & $\begin{array}{c}\text { P1-P3 } \\
\text { (6-bit) }\end{array}$ & $\begin{array}{c}\text { P3-P5 } \\
\text { (6-bit) }\end{array}$ & $\begin{array}{c}\text { REF } \\
\text { P5 } \\
\text { (10-bit) }\end{array}$ & $\begin{array}{c}\text { P5-P7 } \\
\text { (6-bit) }\end{array}$ & $\begin{array}{c}\text { P7-P9 } \\
\text { (6-bit) }\end{array}$ & $\begin{array}{c}\text { S } \\
\text { (1- } \\
\text { bit) }\end{array}$ \\
\hline
\end{tabular}

This technique provides better pixel correlation (or better prediction) than ADPCM-4P. However, error in recovery of $\mathrm{P} 3 \& \mathrm{P} 7$ pixel propagates in recovery of $\mathrm{P} 1$ \& P9 pixels respectively. This error propagation can be avoiding by calculating the errors before encoding as shown in equation (1) and (2).

$$
\begin{gathered}
\Delta E_{P 3}=D L V\left(E L V\left(I D V_{P I-P 3}\right)\right)-I D V_{P I-P 3} \\
\Delta E_{P 7}=D L V\left(E L V\left(I D V_{P 7-P 9}\right)\right)-I D V_{P 7-P 9}
\end{gathered}
$$

Rather than quantizing P1-P3 \& P7-P9 data, P1$\mathrm{P} 3+\Delta \mathrm{E}_{\mathrm{P} 3} \& \mathrm{P} 7-\mathrm{P} 9-\Delta \mathrm{E}_{\mathrm{P} 7}$ will be quantized respectively. This technique is termed as ADPCM-5P-NEP (no error propagation).

\section{RMSE SIMULATION RESULTS}

Four different 10-bit image-sets covering various contrast ranges are used for simulation purpose. These are shown in Fig. 8. Table 5 shows image parameters [6]. Image $1 \& 2$ can be treated as low contrast images. Image 4 is of very high contrast image. Fig. 9 shows histogram of simulation image-sets.

$$
R M S E=\sqrt{\frac{1}{m \cdot n} \sum_{i=0}^{m-1} \sum_{j=0}^{n-1}\left[I_{R E F}(i, j)-I_{\text {recovered }}(i, j)\right]^{2}}
$$

where $[\mathrm{m} \mathrm{n}]$ is image size. $\mathrm{I}_{\mathrm{REF}}$ is considered reference image-set for simulation purpose, while $I_{\text {recovered }}$ is decompressed image.

$$
\begin{aligned}
& \text { Entropy }(\text { bits/ pixel })=\log _{2}\left[\sum_{i=0}^{1023} i \cdot p(i)\right], \\
& p(i)=\text { probabilixtof } i^{\text {th }} \text { count } \\
& \text { Line Complexity }= \\
& \frac{1}{m(n-1)} \sum_{i=0}^{m} \sum_{j=0}^{n-1}\left|I_{R E F}(i, j+1)-I_{\text {recovered }}(i, j)\right|
\end{aligned}
$$

Line complexity is computed from across track odd pixel data.
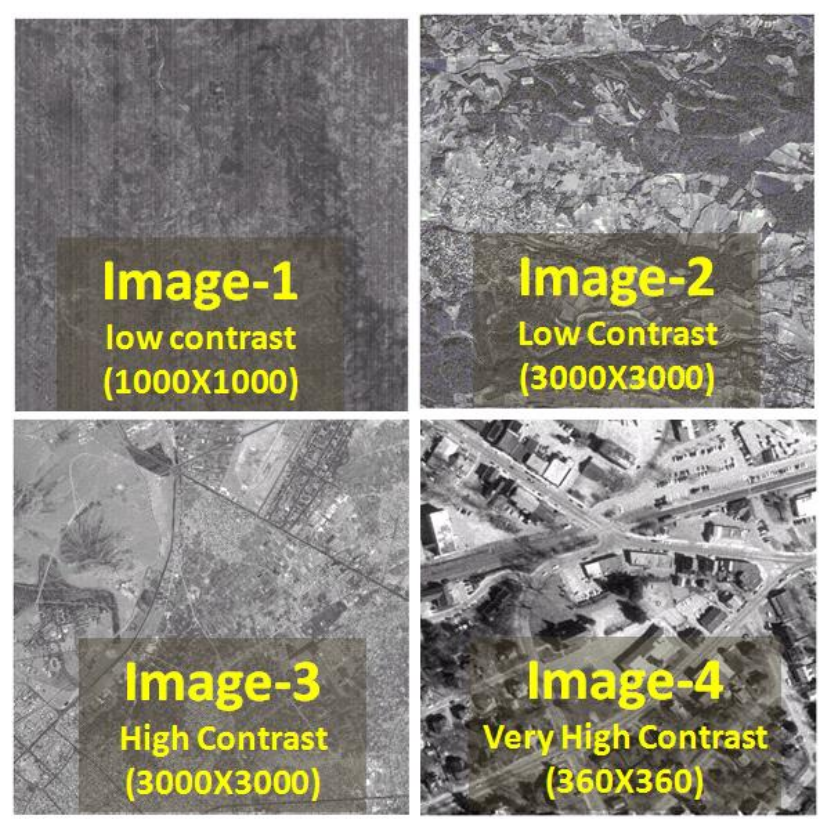

Fig. 8. Image-sets used for simulation
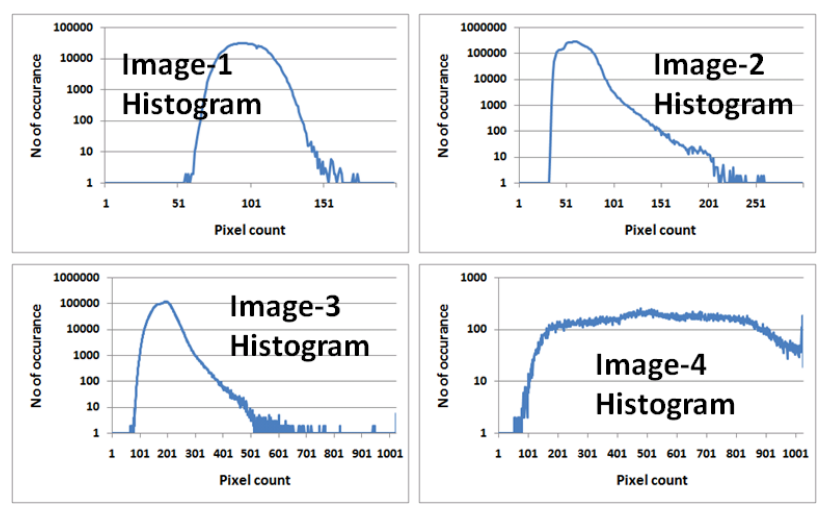

Fig. 9. Histogram of simulation image-sets 
Table 5: Simulation Image-sets parameters

\begin{tabular}{|l|c|c|c|c|c|}
\hline & Mean & $\begin{array}{l}\text { Std. } \\
\text { dev }\end{array}$ & $\begin{array}{l}\text { Max } \\
\text { IDV }\end{array}$ & $\begin{array}{l}\text { IDV } \\
\text { Entropy }\end{array}$ & $\begin{array}{l}\text { Line } \\
\text { Complexity }\end{array}$ \\
\hline $\begin{array}{l}\text { Imagel } \\
\text { (1000X1000) }\end{array}$ & 97.4 & 11.9 & 71 & 3.4 & 8.1 \\
\hline $\begin{array}{l}\text { Image2 } \\
(\text { 3000X3000) }\end{array}$ & 60.1 & 12.4 & 182 & 2.5 & 4.3 \\
\hline $\begin{array}{l}\text { Image3 } \\
\text { (3000X3000) }\end{array}$ & 184.6 & 32.5 & 799 & 3.9 & 13 \\
\hline $\begin{array}{l}\text { Image4 } \\
\text { (360X360) }\end{array}$ & 553.5 & 221.1 & 794 & 6.5 & 95.8 \\
\hline
\end{tabular}

Simulation results are shown in Fig. 10. Due to lossless quantizer, proposed ADPCM techniques achieve much better radiometric performance for low contrast images. Proper dynamic range coverage of quantizer helps in achieving better RMSE performance for very high contrast images. Peak error perforamcne is shown in Fig. 11. These results are verified with the recovered pixel statistics from ADPCM-5P \& ADPCM-4P. This is shown in Fig. 12 \& 13. For image-1 \& 2, lossless encoding of $>99 \%$ pixels leads to RMSE error of $<0.15$ LSB. Kindly note that Existing DPCM technique recovers fixed $25 \%$ pixels as lossless.

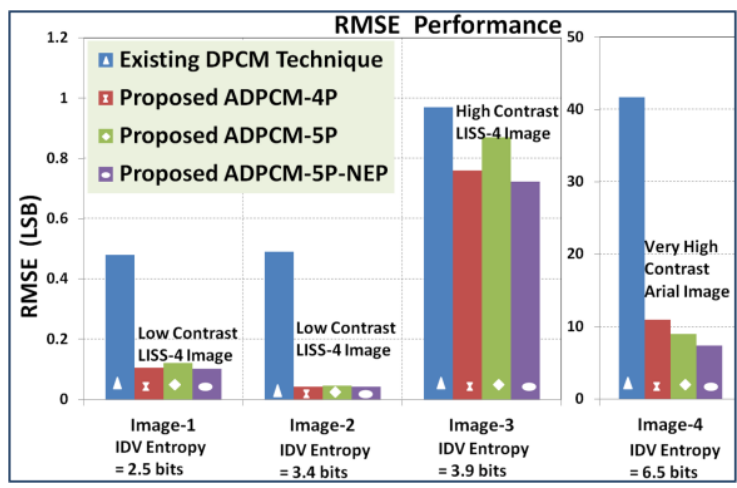

Fig. 10. RMSE performance comparison

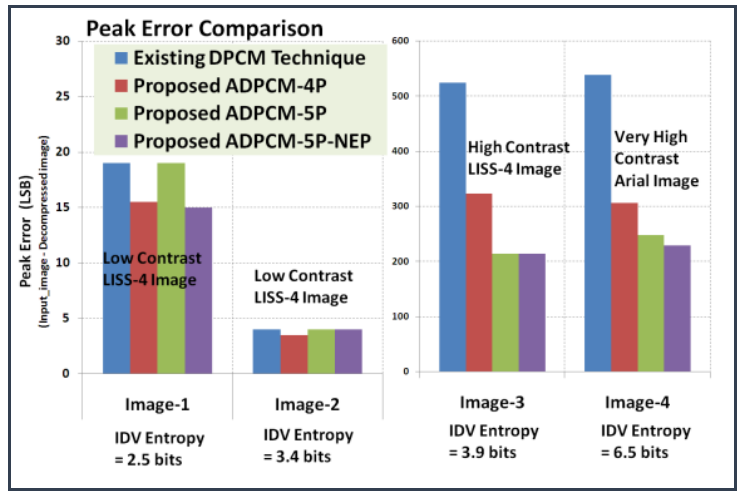

Fig. 11. Peak Error Performance Comparison

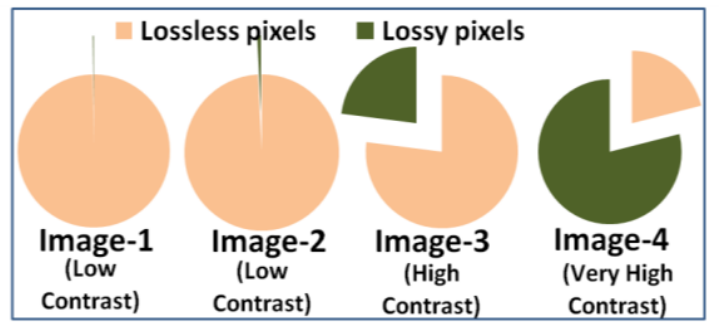

Fig. 12. Recovered data statistics with ADPCM-5P

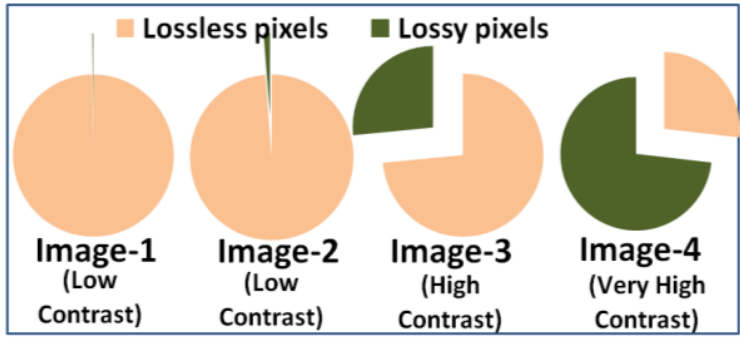

Fig. 13. Recovered data statistics with ADPCM-4P

\section{Ringing ARtifacts Simulation Results}

12 pixel one dimensional worst case simulation dataset is developed as per system MTF. In uniform regions, ringing artifacts are computed by using Equation 6. Fig. 14 shows simulation results. Proposed ADPCM technique reduce ringing artifacts to $<1.5 \%$.

RingingArtifacts $(R A \%)=\frac{P_{n}-\frac{\left(P_{n-1}+P_{n+1}\right)}{2}}{\frac{\left(P_{n-1}+P_{n+1}\right)}{2}} * 100$

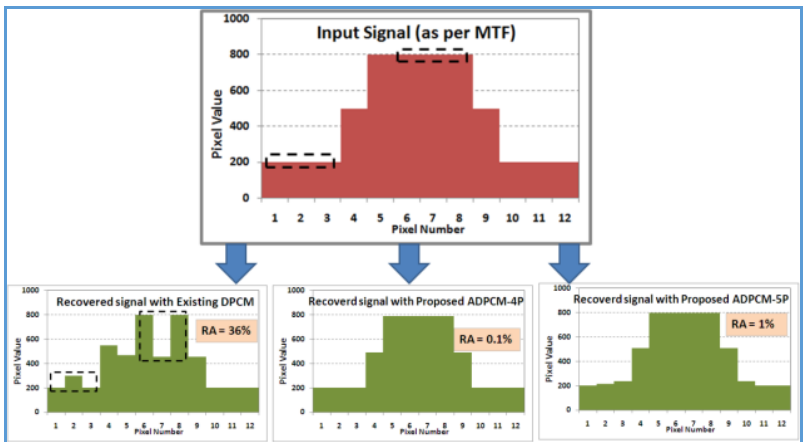

Fig. 14. Ringing artifact simulation with 12-pixel one dimensional data

Simulation dataset (8X8 pixel matrix) with maximum contrast is developed as per LISS-4 system MTF [3]. Fig. 15 shows simulation results (color mapped). In uniform along track and across track regions, ringing artifacts are computed by using Equation 6. Proposed ADPCM techniques reduce ringing artifacts to $<1.5 \%$.

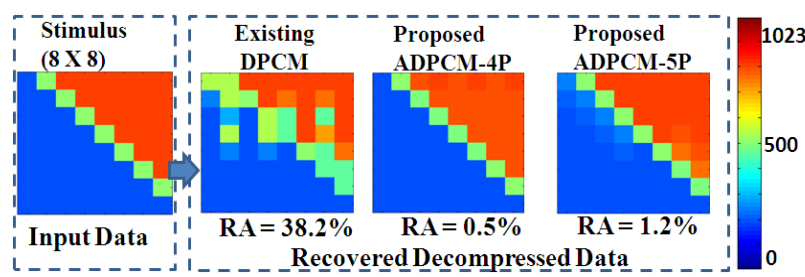

Fig. 15. Ringing Artifacts Simulation with 8 X8 matrix (2-D dataset)

In recovered image 1 to 4 [Fig. 8], no visual ringing artifacts were observed. For visual analysis, some artificial high intensity objects were inserted in image-4. Recovered images are shown in Fig. 16. It can be concluded that ADPCM reduces ringing artifacts significantly. 


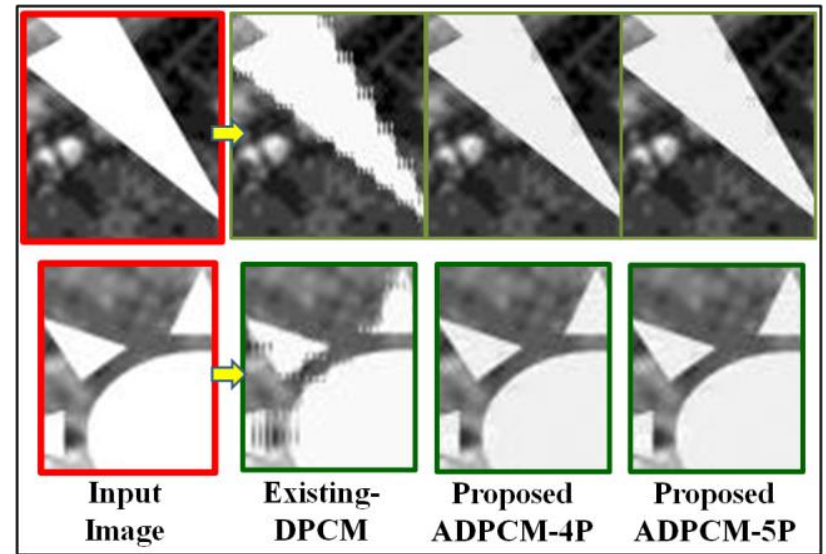

Fig. 16. Ringing Artifacts simulation results on image-4

From above analysis, it can be noted that ringing artifacts cannot be eliminated fully, as these arise because of quantization. Artifact pattern and its extent depend on encoding technique and quantization table. Other space agencies have also reported DPCM noise in recovered image. Fig. 17 shows noise due to ADPCM compression, reported for IKONOS PAN images [7, 8].

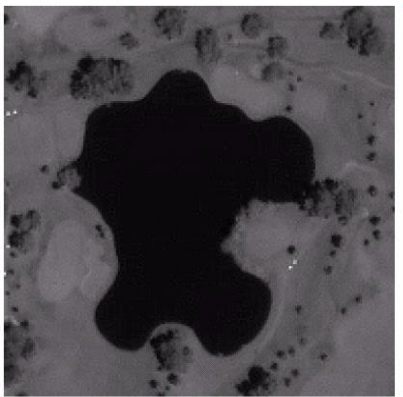

lake in Reid Park, Tucson

Fig. 17. DPCM noise observed in IKONOS PAN Image

\section{CONCLUSION}

The proposed novel ADPCM techniques shows better image reproducibility compared to existing DPCM technique. New ADPCM techniques maintain the compression ratio of 10:7 and achieve significant radiometric improvement on low as well as high contrast images compared to existing DPCM technique. Developed ADPCM techniques produce RMSE of 10 counts compared to 41 counts for very high contrast image. These produces RMSE of 0.04 counts compared to 0.48 counts with low contrast images. Ringing artifacts are reduced to $0.5 \%$ compared to $38.2 \%$. Algorithm of both techniques has low complexity.

\section{ACKNOWLEDGMENT}

We gratefully acknowledge the constant encouragement and guidance received from Shri Arup Roy Chowdhury - GD-SEG, Shri R M Parmar-DD-SRA, Shri DRM Samudraiah- Prof. Satish Dhawan Scientist, Shri Saji A Kuriakose-DD-SEDA and Shri A. S. Kiran Kumar-Director SAC. We are thankful to our colleagues of Payload Checkout Electronics Group for providing the images.

\section{REFERENCES}

[1] Guoxia $\mathrm{Yu}$, Tanya Vladimirova: 'Image Compression systems on board satellites', Acta Astronautica, vol 64, pp 988-1005, 2009.

[2] Deviprasad: "Indian Remote Sensing SatellitesResourcesat2 Mission Status', India Civil Commercial Imagery Evaluation Workshop, March 17, 2010.

[3] Ashok Kumar, Rajiv Kumaran: 'Improvement in DPCM image Compression Technique', International Conference on Information Technology in Signal and Image Processing (itSIP)-2013, 18-19 Oct-2013, Mumbai-India, pp 280-284.

[4] Ashok Kumar, Rajiv Kumaran: 'A low complex ADPCM image compression technique with higher compression ratio', International Journal of Computer Engineering and Technology, Vol 4 Issue 6, Nov-Dec (2013), pp 367377.

[5] Majid Rabbani: 'Digital Image Compression Techniques', Eastman Kodak Company, Volume TT 7, Spie Optical Engineering Press, 1995.

[6] Rafel C Gonzalez, "Digital Image Processing using MATLAB".

[7] Bernd Girod, "EE398B - Image Communication II", a presentation data.

[8] Robert A. Schowengerdt "ECE/OPTI533 Digital Image Processing class notes", a presentation data.

\section{Authors' Profiles}

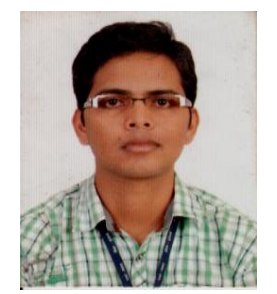

Ashok Kumar, male, is a Scientist/Engineer at Space application Centre (ISRO). He completed his BE degree (Electronics and communication) from University of Rajasthan in 2007. He is currently involved in advance research and development activities for future electro-optical payloads at Sensor Front End Electronics Division (Sensor Development Area). His research interest includes VLSI design, image processing, computation photography etc. He has been awarded "ISRO team excellence award-2009" for "Miniaturized camera electronics development. He has published 9 papers in various international/national conferences and peer reviewed journals.

Contacts:

4396, SFED/SEG/SEDA, Space Applications Centre, Jodhpur

Tekra, Ahmedabad-380015

Phone- 91-79-26914396

Email: ashokkumar@sac.isro.gov.in

Rajiv Kumaran, male, is a Scientist/Engineer at Space application Centre (ISRO). He passed his BE (E\&C) from GEC, Modasa. He joined Space Applications Center (SAC) in April 2000. Presently he is working on design and development of electronics for IRS payloads. 